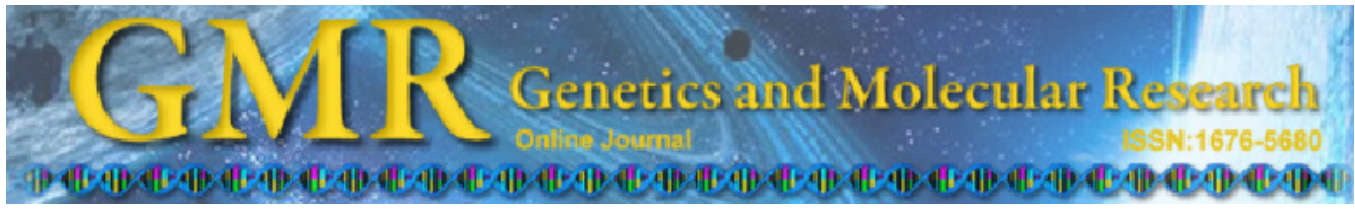

\title{
Prevalence and genotypic diversity of cervical human papillomavirus infection among women from an urban center in Brazil
}

\author{
J. Coser ${ }^{1,3}$, T. da Rocha Boeira ${ }^{2}$, D. Simon ${ }^{1}$, A.S. Kazantzi Fonseca ${ }^{2}$, \\ N. Ikuta ${ }^{1,2}$ and V.R. Lunge ${ }^{1,2}$ \\ ${ }^{1}$ Programa de Pós-Graduação em Biologia Celular e Molecular Aplicada à Saúde, \\ Laboratório de Diagnóstico Molecular, Universidade Luterana do Brasil, \\ Canoas, RS, Brasil \\ ${ }^{2}$ Simbios Biotecnologia, Canoas, RS, Brasil \\ ${ }^{3}$ Curso de Biomedicina, Universidade de Cruz Alta, Cruz Alta, RS, Brasil \\ Corresponding author: V.R. Lunge \\ E-mail: lunge@ulbra.br
}

Genet. Mol. Res. 12 (4): 4276-4285 (2013)

Received August 24, 2012

Accepted November 23, 2012

Published February 19, 2013

DOI http://dx.doi.org/10.4238/2013.February.19.3

\begin{abstract}
Human papillomavirus (HPV) infection is a common viral sexually transmitted infection and the main cause of cervical cancer in women worldwide. Epidemiological data on the prevalence of HPV in a given population is essential for the establishment of effective prevention strategies. The aim of this study was to determine HPV prevalence in women who attended a public health service within an urban center in Brazil. Cervical samples were collected from 337 women recruited from a primary public health care clinic in the city of Cruz Alta located in Rio Grande do Sul, the southernmost State of Brazil. Samples were analyzed for HPV DNA and with Pap smear screening tests. HPV was detected in 114 (34\%) women. HPV type analysis revealed that 95 (83.3\%) of those represented infections with a single genotype, while 19 (16.7\%) were mixed genotype infections. High- and low-risk HPV genotypes
\end{abstract}


were detected in $83(72.8 \%)$ and $48(42.1 \%)$ samples, respectively. Furthermore, a great diversity of HPV genotypes was observed (18 high-risk, 12 low-risk, and 1 indeterminate). The most commonly identified low-risk types were candHPV62 (7.9\%) and 61 (5.3\%), while the most common high-risk types were 16 and 33 ( $8.8 \%$ each). Abnormal cytology was observed in 10 (3.0\%) women, 9 of which were infected with HPV. Of the remaining 327 women with normal cytology results, 107 (32.7\%) were positive for HPV DNA. HPV infection was correlated with younger age (less than 40 years), a first Pap smear, and other vaginal infections.

Key words: Papillomavirus infection; Polymerase chain reaction; Epidemiology

\section{INTRODUCTION}

Cervical cancer is one of the most important diseases affecting women worldwide, with approximately 500,000 new cases and 230,000 deaths per year. The Brazilian National Cancer Institute estimated the incidence of new cases of cervical cancer within Brazil to be 17,450 in 2012 (Ministério da Saúde, 2012).

Several epidemiological studies established the main cause of cervical cancer to be persistent infection with certain genotypes of human papillomavirus (HPV) (Muñoz et al., 1992; Bosch et al.; 2002). Although over 100 types of HPV have been identified to date, only HPVs of the alpha-papillomavirus genus have the capability to infect cervix mucosa. HPV types of this genus are divided into two groups based on their oncogenic ability (de Villiers et al., 2004): low-risk types $(6,11,13,32,42,43,44,54,55,61,71$, $72,74,81,83,84$, candHPV85) that are associated with benign genital mucosa and highrisk or oncogenic types $(16,18,26,30,31,33,34,35,39,45,51,52,53,56,58,59$, $66,67,68,69,70,73,82)$ that are associated with squamous intraepithelial lesions and/ or cancer of the cervix (de Villiers et al., 2004). Apart from HPV, several social factors, such as an early onset of sexual activity, the number of sexual partners, a partner's sexual promiscuity, a high number of children, repeated genital infections, a prolonged use of oral contraceptives, and smoking, are associated with the development of cervical cancer (Franco et al., 2001).

The prevalence of HPV infection varies depending on the geographic region of study (Muñoz et al., 2003). The worldwide prevalence in women with normal cytology is approximately 10\% (de Sanjosé et al., 2007), whereas in women with abnormal cytology it is approximately $35 \%$ (Molijn et al., 2005). Studies conducted in several cities and states revealed a prevalence of HPV infection between 24.8 and $35.0 \%$ in Brazil (Nonnenmacher et al., 2002; Fernandes et al., 2008; Krambeck et al., 2008; Lippmann et al., 2010; Oliveira et al., 2010).

The evaluation of which viral genotypes are circulating within a given region is critical for epidemiological purposes and, subsequently, the establishment of public health policies (Schiffman, 2007). A meta-analysis that aimed to estimate the worldwide prevalence and genotypic distribution of HPV in women with normal cytology, found that the five most 
common types, representing 50\% of all HPV infections, are 16, 18, 31, 58, and 52 (de Sanjosé et al., 2007). These data could also be used to estimate the proportion of a population that would be protected by currently available vaccines and help in the identification of the most effective viral control strategy (screening efforts and/or vaccination). The aim of the present study was to evaluate the prevalence of various HPV genotypes in women who attended a public health service in Southern Brazil and, further, to correlate those findings with other cervical cancer risk factors.

\section{MATERIAL AND METHODS}

\section{Patients and clinical samples}

Between January and July of 2010, cervical samples were collected from 337 women who accepted to participate in the study while undergoing routine Pap smear testing at the Center for Women's Health in Cruz Alta, within the Rio Grande do Sul (RS) State. Pregnant women and patients undergoing treatment for cervical lesions were excluded from the study. After each participant gave informed consent, sample collection was performed by a trained nurse. For cytological examination, biological material was collected by scraping the ectocervix and endocervix with an Ayre spatula and/or an endocervical brush, smeared on glass slides and immediately fixed with polyethylene glycol. To test for HPV DNA, an additional sample was collected from each subject using ecto- and endocervical brushes and, subsequently, placed in a buffer solution at $-20^{\circ} \mathrm{C}$. Socio-demographic and clinical information (age, education, contraceptive method, and date of last cytopathologic exam) were obtained using a standard health service questionnaire.

The project proposal entitled "Evaluation of the use of HPV-DNA detection in screening for precancerous lesions and cervical neoplasia in an urban center in Southern Brazil" was approved by the Research Ethics Committee of the University of Cruz Alta (protocol No. 078.0.417-09).

\section{Laboratory procedures}

Cytological examination was performed with the Pap smear test. Samples were blinded and analyzed by two cytologists independently and the results were classified according to the 2001 Bethesda System (Solomon et al., 2002). Concordant results were considered as final diagnoses, while for divergent results a third sample evaluation was performed.

For HPV DNA detection, genomic DNA was first extracted from samples using the silica method (Boom et al., 1990) and then amplified by nested polymerase chain reaction (nested-PCR) as previously described (Coser et al., 2011). Briefly, nested-PCR was performed with two DNA amplification rounds. The first-round was carried out in a reaction volume of $30 \mu \mathrm{L}$ using $2 \mu \mathrm{L}$ template DNA, 1 X PCR buffer (10 mM Tris-HCl, $\mathrm{pH} 8.5,50 \mathrm{mM} \mathrm{KCl}), 1.5$ $\mathrm{mM} \mathrm{MgCl}, 0.0625 \mathrm{mM}$ of each deoxynucleotide triphosphate (dATP, dTTP, dCTP, dGTP), $0.5 \mu \mathrm{M}$ of each primer (primer SB01: 5'-CAAWTRTTYAATAARCCWTATTGG-3'; primer SB02: 5'-AAAAAYTTYCGWCCMARRGG-3'), and 1 U Taq DNA polymerase (Cenbiot Enzimas, Brazil). Amplification was performed in a PE 9700 thermal cycler (Applied Biosystems, USA) with the following reaction conditions: initial denaturation at $95^{\circ} \mathrm{C}$ for $3 \mathrm{~min}, 20$ cycles of $95^{\circ} \mathrm{C}$ for $20 \mathrm{~s}, 40^{\circ} \mathrm{C}$ for $40 \mathrm{~s}$, and $72^{\circ} \mathrm{C}$ for $1 \mathrm{~min}$, followed by a final 
extension at $72^{\circ} \mathrm{C}$ for $5 \mathrm{~min}$. The second amplification (nested) was also carried out in a reaction volume of $30 \mu \mathrm{L}$ using $2 \mu \mathrm{L}$ amplified DNA, $0.25 \mu \mathrm{M}$ MY09/11 primers (Manos et al., 1989), and the rest of the reagents in the concentrations described above. Amplification was performed with the same thermal cycler as above and the following reaction conditions: initial denaturation at $95^{\circ} \mathrm{C}$ for $3 \mathrm{~min}, 35$ cycles of $95^{\circ} \mathrm{C}$ for $20 \mathrm{~s}, 55^{\circ} \mathrm{C}$ for $40 \mathrm{~s}$, and $72^{\circ} \mathrm{C}$ for $1 \mathrm{~min}$, followed by a final extension at $72^{\circ} \mathrm{C}$ for $5 \mathrm{~min}$. Positive and negative sample controls were included in all analyses.

Amplification products were evaluated after electrophoresis on a $10 \%$ polyacrylamide gel stained with silver nitrate. Samples positive for HPV DNA were further subjected to restriction fragment length polymorphism assays with the following restriction enzymes: Pst (New England Biolabs, USA), HaeIII (New England Biolabs), DdeI (New England Biolabs), RsaI (Promega, USA), and Hinfl (New England Biolabs), according to manufacturer instructions. Sample restriction enzyme profiles were determined after electrophoresis on a $10 \%$ polyacrylamide gel stained with silver nitrate and compared to patterns described by Bernard et al. (1994). Two experienced laboratory analysts independently interpreted the results. Samples with indeterminate results were further subjected to sequencing using a Big Dye Terminator Cycle Sequencing Ready Reaction Kit (Life Technologies, USA) and an ABI Prism ${ }^{\circledR}$ 3100 Genetic Analyzer (Applied Biosystems). Nucleotide sequences were edited using the Sequencher software (Gene Code Corp., USA) and aligned together with reference genotypes obtained in GenBank with the MegAlign program (DNAStar, USA). HPV genotypes were deduced from phylogenies generated by the MegAlign program and sequences obtained were additionally compared to previously annotated ones within the GenBank database (www.ncbi. nlm.nih.gov) using the BLAST tool.

Viral genotypes were classified as high-risk $(16,18,26,30,31,33,34,35,39,45,51$, $52,53,56,58,59,66,67,68,69,70,73,82)$ or low-risk $(6,11,13,32,42,43,44,54,55,61$, $71,72,74,81,83,84$, candHPV62, candHPV85, candHPV86, candHPV87, candHPV89) according to de Villiers et al. (2004). Subjects that presented with abnormal cytology results and/ or a positive HPV test were referred to counseling and given medical care.

\section{Data analysis}

Data analysis was conducted using the SPSS version 11.5 software (SPSS Inc., USA). The distribution of HPV genotypes within the study population is presented as frequencies and proportions. Associations between HPV infection status and socio-demographic factors and clinical variables were determined with the chi-square test or the non-parametric test for measuring trends across groups. Tests results with a $\mathrm{P}<0.05$ were considered to be statistically significant.

\section{RESULTS}

Of the 337 women that participated in the study, 114 (34\%) presented with positive HPV DNA detection results: 48 (42.1\%) for at least one low-risk type, $83(72.8 \%)$ at least one high-risk type, and one (0.9\%) for a type that was of indeterminate risk (Table 1). Multiple HPV genotypes (mixed infections) were detected in 19 (16.7\%) of the 114 positive samples, $17(89.5 \%)$ of which tested positive for at least one high-risk type. 


\begin{tabular}{|c|c|c|c|c|}
\hline HPV type & $\begin{array}{l}\text { Single infection } \\
\quad(\mathrm{N}=95)\end{array}$ & $\begin{array}{l}\text { Multiple infection } \\
\qquad(\mathrm{N}=19)\end{array}$ & $\begin{array}{l}\text { All HPV infections } \\
(\mathrm{N}=114)\end{array}$ & $\begin{array}{c}\text { All women } \\
(\mathrm{N}=337)\end{array}$ \\
\hline \multicolumn{5}{|l|}{ High-risk } \\
\hline 16 & 8 & 2 & $10(8.7)$ & $3.0 \%$ \\
\hline 18 & 1 & 7 & $8(7.0)$ & $2.4 \%$ \\
\hline 31 & 6 & 0 & $6(5.3)$ & $1.8 \%$ \\
\hline 33 & 6 & 4 & $10(8.7)$ & $3.0 \%$ \\
\hline 34 & 1 & 0 & $1(0.9)$ & $0.3 \%$ \\
\hline 35 & 3 & 0 & $3(2.7)$ & $0.8 \%$ \\
\hline 39 & 2 & 0 & $2(1.7)$ & $0.5 \%$ \\
\hline 45 & 5 & 1 & $6(5.3)$ & $1.8 \%$ \\
\hline 52 & 3 & 1 & $4(3.6)$ & $1.1 \%$ \\
\hline 53 & 4 & 4 & $8(7.0)$ & $2.4 \%$ \\
\hline 56 & 0 & 1 & $1(0.9)$ & $0.3 \%$ \\
\hline 58 & 3 & 1 & $4(3.6)$ & $1.1 \%$ \\
\hline 59 & 1 & 0 & $1(0.9)$ & $0.3 \%$ \\
\hline 66 & 1 & 1 & $2(1.7)$ & $0.5 \%$ \\
\hline 67 & 1 & 0 & $1(0.9)$ & $0.3 \%$ \\
\hline 70 & 8 & 1 & $9(7.9)$ & $2.8 \%$ \\
\hline 73 & 2 & 4 & $6(5.3)$ & $1.8 \%$ \\
\hline candHPV85 & 1 & 0 & $1(0.9)$ & $0.3 \%$ \\
\hline Total high-risk & $56(67.4)$ & $27(32.6)$ & $83(72.8)$ & $24.5 \%$ \\
\hline \multicolumn{5}{|l|}{ Low-risk } \\
\hline 6 & 1 & 2 & $3(2.7)$ & $0.8 \%$ \\
\hline 11 & 2 & 2 & $4(3.6)$ & $1.1 \%$ \\
\hline 42 & 5 & 0 & $5(4.3)$ & $1.6 \%$ \\
\hline 54 & 3 & 2 & $5(4.3)$ & $1.6 \%$ \\
\hline 55 & 3 & 0 & $3(2.7)$ & $0.8 \%$ \\
\hline 61 & 6 & 0 & $6(5.3)$ & $1.8 \%$ \\
\hline candHPV62 & 8 & 1 & $9(7.9)$ & $2.8 \%$ \\
\hline 71 & 1 & 0 & $1(0.9)$ & $0.3 \%$ \\
\hline 81 & 2 & 2 & $4(3.6)$ & $1.1 \%$ \\
\hline 83 & 1 & 0 & $1(0.9)$ & $0.3 \%$ \\
\hline 84 & 4 & 1 & $5(4.3)$ & $1.6 \%$ \\
\hline candHPV89 & 2 & 0 & $2(1.7)$ & $0.5 \%$ \\
\hline Total low-risk & $38(79.2)$ & $10(20.8)$ & $48(42.1)$ & $14.3 \%$ \\
\hline \multicolumn{5}{|l|}{ Indeterminate } \\
\hline HPV114 & $1(100)$ & 0 & $1(0.9)$ & $0.3 \%$ \\
\hline
\end{tabular}

A total of 31 unique viral genotypes were identified; 18 high-risk and 13 low-risk. The most commonly detected low-risk types were candHPV62 and 61, comprising 7.9 and 5.3\% of the HPV DNA positive samples, respectively. The most commonly detected high-risk types of HPV-positive samples were 16 (8.8\%), 33 (8.8\%), and 70 (7.9\%) (Table 1).

In terms of cytology, $327(97.0 \%)$ and $10(3.0 \%)$ women presented with normal and abnormal samples, respectively. Atypical squamous cells were detected in only $5(1.5 \%)$ study subjects; $3(0.9 \%)$ representing low-grade squamous intraepithelial lesions and $2(0.6 \%)$ representing high-grade squamous intraepithelial lesions (Table 2). Unsurprisingly, women whose samples were positive for the DNA of high-risk HPV types were significantly more likely to present with abnormal cytology than those with samples positive for low-risk HPV DNA or samples negative for HPV DNA. Of the 327 women who presented with normal cytology, 107 (32.7\%) had samples positive for HPV DNA, 64 (59.8\%) of which were positive for a highrisk type (Table 2).

The characteristics of the study population are shown in Table 3 according to HPV infection status. HPV infection was associated with a younger age (less than 40 years), a first 
Pap smear, and the presence of other vaginal infections. A total of $64(19.0 \%)$ study participants had vaginal infections (Gardnerella vaginalis, Candida spp, and Trichomonas vaginalis) in addition to the HPV infection. The use of contraceptive methods (condoms or sterilization) was associated with the absence of HPV infection (Table 3).

Table 2. Cytological diagnosis according to the presence of human papillomavirus (HPV) infection.

\begin{tabular}{lcccc}
\hline Cytological diagnosis & $\begin{array}{c}\text { Without HPV } \\
(\mathrm{N}=220)\end{array}$ & $\begin{array}{c}\text { High-risk HPV } \\
(\mathrm{N}=71)\end{array}$ & $\begin{array}{c}\text { Only low-risk HPV } \\
(\mathrm{N}=45)\end{array}$ & $\begin{array}{c}\text { All women } \\
(\mathrm{N}=337)\end{array}$ \\
\hline NILM & $219(99.5)$ & $64(90)$ & $43(95.6)$ & $327(97)$ \\
ASC-US & $1(0.5)$ & $3(4.2)^{\mathrm{a}}$ & $1(2.2)^{\mathrm{b}}$ & $5(1.5)$ \\
LSIL & $0(0.0)$ & $2(2.9)^{\mathrm{c}}$ & $1(2.2)^{\mathrm{d}}$ & $3(0.9)$ \\
HSIL & $0(0.0)$ & $2(2.9)^{\mathrm{c}}$ & $0(0.0)$ & $2(0.6)$ \\
\hline
\end{tabular}

Data are reported as number with percent in parentheses. NILM $=$ negative for intraepithelial lesion and malignancy; ASC-US = atypical squamous cells; LSIL = low-grade squamous intraepithelial lesion; HSIL = highgrade squamous intraepithelial lesion. ${ }^{a}$ Includes HPV types 35, 59, 70; 'infection HPV type 42; 'two multiple infections with types 73 and 6; 18 and 52; ${ }^{d}$ multiple infection with types 81 and 84; infection HPV types 16 and 33.

Table 3. Characteristics of the population according to human papillomavirus (HPV) status.

\begin{tabular}{lccc}
\hline Characteristic & Overall $(\mathrm{N}=337)$ & With HPV $(\mathrm{N}=114)$ & Without HPV $(\mathrm{N}=223)$ \\
\hline Age (years) & & & \\
$\leq 19$ & $23(6.9)$ & $12(10.6)^{* *}$ & $11(5.0)$ \\
$20-29$ & $70(20.7)$ & $33(28.9)^{* *}$ & $37(16.5)$ \\
$30-39$ & $62(18.3)$ & $28(24.5)^{* *}$ & $34(15.3)$ \\
$40-49$ & $84(25.0)$ & $17(15.0)$ & $67(30.0)$ \\
$50-59$ & $67(19.9)$ & $5(16.7)$ & $48(21.6)$ \\
$\geq 60$ & $31(9.2)$ & $57(50.0)$ & $26(11.6)$ \\
Contraceptive oral use & $122(36.2)$ & $52(45.7)$ & $65(29.2)$ \\
Yes & $203(60.2)$ & $5(4.3)$ & $151(67.8)^{* *}$ \\
No & $12(3.6)$ & $22(19.2)^{* *}$ & $7(3.0)$ \\
Not informed & $42(12.4)$ & $44(38.6)$ & $20(8.9)$ \\
Last CP & $142(42.1)$ & $45(39.5)$ & $98(43.9)$ \\
First time & $136(40.4)$ & $3(2.7)$ & $91(40.9)$ \\
$\leq 1$ year & $17(5.1)$ & $34(29.8)$ & $14(6.3)$ \\
$\geq 2$ years & $64(18.9)$ & $80(70.2)$ & $30(13.5)$ \\
Not informed & $273(81.1)$ & $193(86.5)$ \\
Concurrent vaginal infection* & Yes & & \\
No & & &
\end{tabular}

Data are reported as number with percent in parentheses. $\mathrm{CP}=$ cytological test; ${ }^{*}$ Gardnerella vaginalis, Candida spp, Trichomonas vaginalis diagnosed by cytology. ${ }^{* *}$ Significant at $\mathrm{P}<0.05$.

\section{DISCUSSION}

The prevalence of HPV infection has been studied in some regions and cities within Brazil. Most of these earlier studies involved women who previously presented with abnormal cervical cytology results and were consequently seeking health service for disease screening or treatment (Ayres and Silva, 2010). The few studies on HPV infection prevalence in healthy female populations (as determined by cervical cytology) revealed an overall prevalence ranging from 11 to 35\% (Lipmann et al., 2010; Miranda et al., 2012). The results of the present study identified a HPV infection prevalence of $34 \%$ in women attending a public health service in Cruz Alta. This result is, therefore, amongst the highest HPV prevalence values 
observed in Brazil to date and likely reflects the use of nested-PCR assays for data gathering, a method that has a higher analytical sensitivity compared with other HPV DNA detection strategies (Lipmann et al., 2010; Coser et al., 2011). Our HPV prevalence finding was also slightly higher than those previously found in populations within in the State of Rio Grande do Sul by PCR and hybrid capture analysis (Nonnenmacher et al., 2002; Rosa et al., 2008).

Cervical HPV infections are mostly attributed to high-risk genotypes. In the present study, high-risk types accounted for $72.8 \%$ of all the HPV DNA positive samples, representing single and mixed infections. This finding was slightly higher than the previously reported values of 61 and $57.8 \%$ in other Brazilian cities (São Paulo and Ouro Preto, respectively) (Lippmann et al., 2010; Miranda et al., 2012). However, the prevalence of the HPV types was not so consistent with other reports. A meta-analysis has revealed that HPV 16 is the most common genotype found among women presenting with normal cervical cytology worldwide (de Sanjosé et al., 2007). Furthermore, a multicenter analysis of young women presenting with normal cervical cytology from Brazil, Canada, and the USA also determined HPV 16 to be the most prevalent genotype (Roteli-Martins et al., 2011). In Brazil, this type was also found to be the most prevalent, ranging from 18.6 to $52.2 \%$ within the women population in different cities (Rosa et al., 2008; Oliveira et al., 2010; Castro et al., 2011; Baldez da Silva et al., 2012). Although our results revealed that HPV 16, along with HPV 33, was the most prevalent genotype in our study population within Cruz Alta, the frequency of this genotype was not so high $(8.7 \%)$ in comparison to those noted in earlier reports. Other highly prevalent types identified here were candHPV62 and HPV 70, each representing 7.9\% of infections, and HPV 18 and HPV 53, each representing 7.0\% of infections. A high diversity of HPV types $(\mathrm{N}=31)$ was observed with frequencies of 0.9 to $8.7 \%$. The observed greater heterogeneity of HPV types is probably due to regional population differences (Ayres and Silva, 2010).

Mixed HPV infections (infections containing more than one type simultaneously) were detected in $16.7 \%$ of women with samples positive for HPV DNA in our study. This finding was slightly lower than the frequency of mixed infections $(25.7 \%)$ observed in a study conducted in Porto Alegre (de Souza, 2004). Of note, we recruited women with between the ages of 13 and 82 years, while only young women, aged between 15 and 25 years, participated in the previous study. Mixed infections are generally more common in young women: Rousseau et al. (2003) found a prevalence of $27.0 \%$ among women 18 to 24 years of age and a prevalence of $5.6 \%$ among women 45 to 60 years of age.

The investigation of HPV genotypic diversity within a city or a region is important for the establishment of effective preventative strategies against cervical cancer, in terms of diagnostic procedures and prophylactic actions (vaccination). Currently, the Hybrid Capture ${ }^{\circledR}$ test is the method used most often to detect HPV DNA in clinical samples. Of the 31 viral types identified in our study, 17 (34, 53, 54, 55, 61, candHPV62, 66, 67, 70, 71, 73, 81, 83, 84, candHPV85, candHPV89, HPV114) representing $19.3 \%$ of all samples and $57.0 \%$ of the HPV DNA positive samples and which include 7 high-risk types $(34,53,66,67,70,73$, candHPV85) are not within the detection spectrum of the Hybrid Capture ${ }^{\mathbb{B}}$ test. Furthermore, a recent study comparing PCR and hybrid capture methods demonstrated the higher sensitivity of PCR to detect HPV DNA in clinical samples (Rodrigues et al., 2009). Taken together, these findings justify the use of PCR as a tool for gathering information on HPV infection.

The two vaccines currently available to prevent HPV infection are being used in Brazil. Cervarix ${ }^{\circledR}$ (GlaxoSmithKline), the bivalent vaccine, protects against genotypes 16 and 
18, while Gardasil ${ }^{\circledR}$ (Merck Sharp \& Dohme), the quadrivalent vaccine, provides protection against viral types 6,11, 16, and 18 (Lowy and Shiller, 2006). Further, there is some evidence that these vaccines offer cross-protection against infections with types $31,33,45,52$, and 58 (Bonanni et al., 2009). In the present study, $15.8 \%$ of the participants presenting with an HPV infection had either type 16 or 18 (the types included in the bivalent vaccine), $21.9 \%$ had types $6,11,16$, or 18 (the types included in the quadrivalent vaccine), and $26.3 \%$ had other types that the vaccines may cross-protected against (types $45,31,33,52,58$ ). Therefore, only a small proportion of the subjects were infected with HPV types that are covered by the currently available vaccines.

Considering clinical characteristics, we found that $32.7 \%$ of women presenting with normal cervical cytology were infected with HPV. This frequency is higher than those reported in other Brazilian studies, where the prevalence of HPV infection was between 10.4 and $24.5 \%$, as reported in a recently published systematic review (Ayres and Silva, 2010). This difference is likely related to the high analytical sensitivity of the assay (nested-PCR) used in the present study. In women presenting with cervical cytological abnormalities, the prevalence of HPV infection was $100 \%$ and, in all cases, was attributed to high-risk types.

Investigation of factors associated with HPV infections is also important for the understanding of the natural history of infection within a given population (Burd, 2009). Some general demographic data of the female population studied were, therefore, also collected and analyzed. With respect to age, there were a higher proportion of HPV infection positive women in the group aged less than 40 years in comparison to the group over this age ( $\mathrm{P}$ $<0.05)$. It is important to note that the high prevalence of HPV infections among younger women generally reflects transient infections, while the decreased prevalence in subjects between 30 and 40 years of age may be related to their reduced exposure to new partners and/ or acquired immunity towards certain types of HPV (Muñoz et al., 2006). In women aged 30 years or more, however, presence of the virus can also reflect a persistent infection, which would require more attention in the clinical management (Rama et al., 2008). The results of the present study also revealed a higher proportion of women infected with HPV among those who indicated they were making their first Pap smear exam when compared to women with two or more routine tests $(\mathrm{P}<0.05)$. Periodic visits to clinicians and routine Pap smear testing has been previously associated with a reduced risk for the development of cervical cancer: sexually active women who never received this examination had a high risk of developing cervical cancer (Gontijo et al., 2004).

A significantly higher prevalence of HPV infection was also found in women using oral contraceptive methods. The use of oral contraceptives as a risk factor for HPV infection is unclear as divergent data exists within the literature, with positive (Molano et al., 2003) and negative associations (Peyton et al., 2001) having been noted. In the present study, a greater proportion of alternative contraceptive methods (condoms and tubal ligation) were used in women not infected with HPV $(\mathrm{P}<0.05)$. Previous studies conducted within Brazil and in other countries have not found a significant association between condom use and infection with HPV (Peyton et al., 2001; Molano et al., 2003; de Souza 2004). Moreover, a meta-analysis conducted by Manhart and Koutsky (2002) showed no consistent evidence for condom use reducing the risk of HPV infection.

In terms of other vaginal infections, the frequency of G. vaginalis (bacterial vaginosis), Candida spp, and T. vaginalis was significantly higher among women infected than women not 
infected with HPV $(\mathrm{P}<0.05)$. There is no data within published literature to indicate that HPV infection affects the growth of $G$. vaginalis in vaginal flora. Some studies do, however, report a higher incidence of infection with G. vaginalis (Murta et al., 2000; Mao et al., 2003; Lippman et al., 2010) and Candida spp (Nogueres et al., 2010) when HPV infection is present.

In conclusion, the present study advances our understanding of HPV infection epidemiology. The HPV prevalence and genotypic distribution within an urban center in RS was determined and, subsequently, established a profile of women who should seek public health service for cervical cancer screening routinely. These findings may aid in the identification of person groups that are most vulnerable to infection by HPV and to enable the screening of women who have a higher risk of developing cervical lesions, contributing in the design of effective preventative strategies within this population.

\section{ACKNOWLEDGMENTS}

The authors thank the staff and physicians of the Center for Women's Health in Cruz Alta, RS, for their collaboration.

\section{REFERENCES}

Ayres AR and Silva GA (2010). Cervical HPV infection in Brazil: systematic review. Rev. Saude Publica 44: 963-974. Baldez da Silva MF, Guimaraes V, Silva MA, Medeiros do Amaral CM, et al. (2012). Frequency of human papillomavirus types 16, 18, 31, and 33 and sites of cervical lesions in gynecological patients from Recife, Brazil. Genet. Mol. Res. 11: $462-466$.

Bernard HU, Chan SY, Manos MM, Ong CK, et al. (1994). Identification and assessment of known and novel human papillomaviruses by polymerase chain reaction amplification, restriction fragment length polymorphisms, nucleotide sequence, and phylogenetic algorithms. J. Infect. Dis. 170: 1077-1085.

Bonanni P, Boccalini S and Bechini A (2009). Efficacy, duration of immunity and cross protection after HPV vaccination: a review of the evidence. Vaccine 1 (Suppl 27): A46-A53.

Boom R, Sol CJ, Salimans MM, Jansen CL, et al. (1990). Rapid and simple method for purification of nucleic acids. $J$. Clin. Microbiol. 28: 495-503.

Bosch FX, Lorincz A, Munoz N, Meijer CJ, et al. (2002). The causal relation between human papillomavirus and cervical cancer. J. Clin. Pathol. 55: 244-265.

Burd EM (2003). Human papillomavirus and cervical cancer. Clin. Microbiol. Rev. 16: 1-17.

Castro MM, Farias IP, Borborema-Santos CM, Correia G, et al. (2011). Prevalence of human papillomavirus (HPV) type 16 variants and rare HPV types in the central Amazon region. Genet. Mol. Res. 10: 186-196.

Coser J, Boeira TR, Fonseca AS, Ikuta N, et al. (2011). Human papillomavirus detection and typing using a nested-PCRRFLP assay. Braz. J. Infect. Dis. 15: 467-472.

de Sanjosé S, Diaz M, Castellsague X, Clifford G, et al. (2007). Worldwide prevalence and genotype distribution of cervical human papillomavirus DNA in women with normal cytology: a meta-analysis. Lancet Infect. Dis. 7: 453-459.

de Souza EP (2004). Epidemiologia da Infecção Genital por HPV e Anormalidades na Citologia Cervical em Mulheres Jovens Brasileiras. Doctoral thesis, Faculdade de Ciências Médicas, Universidade Estadual de Campinas (UNICAMP), Campinas.

de Villiers EM, Fauquet C, Broker TR, Bernard HU, et al. (2004). Classification of papillomaviruses. Virology 324: 17-27.

Fernandes TAAM, de Vasconcellos RM, Bezerra LF, de Azevedo PRM, et al. (2008). Human papillomavirus infection in women attended at a cervical cancer screening service in Natal, Brazil. Braz. J. Microbiol. 39: 573-578.

Franco EL, Duarte-Franco E and Ferenczy A (2001). Cervical cancer: epidemiology, prevention and the role of human papillomavirus infection. CMA J. 164: 1017-1025.

Gontijo R, Martins CR, Derchain S, Bragança JF, et al. (2004). Sexual behaviour and age as risk factors for intraepithelial and invasive uterine cervical lesion. Rev. Cienc. Med. 13: 13-21.

Krambeck WM, Cadide RM, Dalmarco EM and de Cordova CM (2008). HPV detection and genotyping as an earlier approach in cervical cancer screening of the female genital tract. Clin. Exp. Obstet. Gynecol. 35: 175-178. 
Lippman SA, Sucupira MC, Jones HE, Luppi CG, et al. (2010). Prevalence, distribution and correlates of endocervical human papillomavirus types in Brazilian women. Int. J. STD AIDS 21: 105-109.

Lowy DR and Schiller JT (2006). Prophylactic human papillomavirus vaccines. J. Clin. Invest. 116: 1167-1173.

Manhart LE and Koutsky LA (2002). Do condoms prevent genital HPV infection, external genital warts, or cervical neoplasia? A meta-analysis. Sex. Transm. Dis. 29: 725-735.

Manos MM, Ting Y, Wright DK, Lewis AI, et al (1989). Use of polymerase chain reaction amplification for the detection of genital human papillomaviruses. Cancer Cells 7: 209-214.

Mao C, Hughes JP, Kiviat N, Kuypers J, et al. (2003). Clinical findings among young women with genital human papillomavirus infection. Am. J. Obstet. Gynecol. 188: 677-684.

Ministério da Saúde (2012). Estimativas 2012: Incidência de Câncer no Brasil. Available at: [http://www.inca.gov.br/ estimativa/2012/estimativa20122111.pdf]. Accessed June 17, 2012. Rio de Janeiro.

Miranda PM, Pitol BC, Moran MS, Silva NN, et al. (2012). Human papillomavirus infection in Brazilian women with normal cervical cytology. Genet. Mol. Res. 11: 1752-1761.

Molano M, Van den Brule A, Plummer M, Weiderpass E, et al. (2003). Determinants of clearance of human papillomavirus infections in Colombian women with normal cytology: a population-based, 5-year follow-up study. Am. J. Epidemiol. 158: 486-494.

Molijn A, Kleter B, Quint W and van Doorn LJ (2005). Molecular diagnosis of human papillomavirus (HPV) infections. J. Clin. Virol. 1 (Suppl 32): S43-S51.

Muñoz N, Bosch FX, de Sanjosé S, Tafur L, et al. (1992). The causal link between human papillomavirus and invasive cervical cancer: a population-based case-control study in Colombia and Spain. Int. J. Cancer 52: 743-749.

Muñoz N, Bosch FX, de Sanjosé S, Herrero R, et al. (2003). Epidemiologic classification of human papillomavirus types associated with cervical cancer. N. Engl. J. Med. 348: 518-527.

Muñoz N, Castellsague X, de Gonzalez AB and Gissmann L (2006). Chapter 1: HPV in the etiology of human cancer. Vaccine 3 (Suppl 24): S3-1-S310.

Murta EF, Souza MA, Araujo JE and Adad SJ (2000). Incidence of Gardnerella vaginalis, Candida sp and human papilloma virus in cytological smears. Sao Paulo Med. J. 118: 105-108.

Nogueres IB, Zimmermann JB, Gonçalves LG, Fontes LC, et al (2010). Associação entre a infecção pelo papilomavírus humano (HPV) e outras infecções genitais femininas. HU Rev. Juiz de Fora 36: 19-28.

Nonnenmacher B, Breitenbacha V, Villa LL, Prolla JC, et al. (2002). Identificação do papilomavírus humano por biologia molecular em mulheres assintomáticas. Rev. Saude Publica 36: 95-100.

Oliveira LH, Ferreira MD, Augusto EF, Melgaco FG, et al. (2010). Human papillomavirus genotypes in asymptomatic young women from public schools in Rio de Janeiro, Brazil. Rev. Soc. Bras. Med. Trop. 43: 4-8.

Peyton CL, Gravitt PE, Hunt WC, Hundley RS, et al. (2001). Determinants of genital human papillomavirus detection in a US population. J. Infect. Dis. 183: 1554-1564.

Rama CH, Roteli-Martins CM, Derchain SFM, Longatto-Filho A, et al. (2008). Prevalência do HPV em mulheres rastreadas para o câncer cervical. Rev. Saude Publica 42: 123-130.

Rodrigues AD, Cantarelli VV, Frantz MA, Pilger DA, et al. (2009). Comparação das técnicas de captura de híbridos e PCR para a detecção de HPV em amostras clínicas. J. Bras. Patol. Med. Lab. 45: 457-462.

Rosa MI, Fachel JM, Rosa DD, Medeiros LR, et al. (2008). Persistence and clearance of human papillomavirus infection: a prospective cohort study. Am. J. Obstet. Gynecol. 199: 617.

Roteli-Martins CM, de Carvalho NS, Naud P, Teixeira J, et al. (2011). Prevalence of human papillomavirus infection and associated risk factors in young women in Brazil, Canada, and the United States: a multicenter cross-sectional study. Int. J. Gynecol. Pathol. 30: 173-184.

Rousseau MC, Villa LL, Costa MC, Abrahamowicz M, et al. (2003). Occurrence of cervical infection with multiple human papillomavirus types is associated with age and cytologic abnormalities. Sex. Transm. Dis. 30: 581-587.

Schiffman M (2007). Integration of human papillomavirus vaccination, cytology, and human papillomavirus testing. Cancer 111: 145-153.

Solomon D, Davey D, Kurman R, Moriarty A, et al. (2002). The 2001 Bethesda System: terminology for reporting results of cervical cytology. JAMA 287: 2114-2119. 